\title{
Prioritization of Variants for Investigation of Genotype-Directed Nutrition in Human Superpopulations
}

\author{
Pascal D. Nilsson ${ }^{1,+} \mathbb{D}$, Jacklyn M. Newsome ${ }^{1,+} \mathbb{D}$, Henry M. Santos ${ }^{1}$ and \\ Martin R. Schiller 1,2,*iD \\ 1 Nevada Institute of Personalized Medicine and School of Life Sciences, University of Nevada Las Vegas, \\ Las Vegas, NV 89154-4004, USA \\ 2 Food Genes and Me LLC, 929 Via Doccia Court. Henderson, NV 89011, USA \\ * Correspondence: martin.schiller@unlv.edu \\ + These authors contributed equally to this manuscript.
}

Received: 14 May 2019; Accepted: 16 July 2019; Published: 18 July 2019

check for updates

\begin{abstract}
Dietary guidelines recommended by key health agencies are generally designed for a global population. However, ethnicity affects human disease and environment-gene interactions, including nutrient intake. Historically, isolated human populations with different genetic backgrounds have adapted to distinct environments with varying food sources. Ethnicity is relevant to the interaction of food intake with genes and disease susceptibility; yet major health agencies generally do not recommend food and nutrients codified by population genotypes and their frequencies. In this paper, we have consolidated published nutrigenetic variants and examine their frequencies in human superpopulations to prioritize these variants for future investigation of population-specific genotype-directed nutrition. The nutrients consumed by individuals interact with their genome and may alter disease risk. Herein, we searched the literature, designed a data model, and manually curated hundreds of papers. The resulting database houses 101 variants that reached significance $(p<0.05)$, from 35 population studies. Nutrigenetic variants associated with modified nutrient intake have the potential to reduce the risk of colorectal cancer, obesity, metabolic syndrome, type 2 diabetes, and several other diseases. Since many nutrigenetic studies have identified a major variant in some populations, we suggest that superpopulation-specific genotype-directed nutrition modifications be prioritized for future study and evaluation. Genotype-directed nutrition approaches to dietary modification have the potential to reduce disease risk in select human populations.
\end{abstract}

Keywords: nutrigenetics; gene-diet interaction; nutrient; superpopulation; SNP

\section{Introduction}

As genomics holds promise to transform global health and medicine, there is a growing interest in the relationship between genotype and phenotype. Phenotype is derived from both genetic and environmental contributions. The most common environmental influences on phenotype are direct exposure to pathogens and nutrient intake. Herein, we focus on human nutrigenetics. Food-based dietary guidelines are periodically developed by global organizations, especially the Food and Agricultural Organization (FAO) of the United Nations and World Health Organization (WHO). These organizations play a vital role in shaping food policies and guidelines globally, considering unique cultures, food availability, eating habits, food safety, and other factors for each country.

There is mounting evidence that human behavior of diet selection is hereditary. Measurements of heritability separate the genetic and environmental components of any disease or trait. Approximately 
$60 \%-80 \%$ of the variability in human height is genetically derived with $20 \%-40 \%$ coming from the environment [1]. The heritability is higher in developed countries and lower in developing countries, inferring that the environmental differences are nutrition-based. Consistent with these estimates, the general heritability of food intake patterns is $27 \%-32 \%$ [2]. Other more focused studies impart further support. The heritability of food intake in the Chinese population ranges from 19\%-95\% depending on types of food and gender [3]. A $12 \%-24 \%$ heritability of eicosapentaenoic acid (EPA) and docosahexaenoic acid (DHA) consumption was identified by a meta-analysis of 17 cohorts $[4,5]$. The heritability of choosing bread as a food source in Danish and Finnish cohorts ranges from $23 \%-45 \%$ [6].

Once a genetic component of a trait or disease is identified, the next challenge is to decode the genetic variation that explains the heritability, focusing most often on the contributions of individual genes and alleles and more recently on epigenetic changes. This has not yet been well-characterized for human dietary patterns. Very little is known about nutrigenetic variants that affect disease in different populations. Polymorphisms in several genes associated with folate and alcohol consumption, and colon cancer risk have different frequencies in Caucasians and African Americans [7]. There are ethnic effects on plasma polyunsaturated fatty acid levels and preferences for plant protein consumption $[8,9]$. Although not associated with disease, a principal component analysis identified dietary-driven differences in high abundance plasma proteins among ethnic groups [10]. This study identifies published nutrigenetic variants that have large genotypic differences in different superpopulations [10].

There are new opportunities to explore the role of genetics in the human diet that are supported by strong evidence. The recently reduced cost of sequencing a human genome, exome, microarrays, and genotyping has advanced the understanding of human genetic variation. Variants from $>2400$ genome-wide association studies (GWAS) consolidated in the GWAS catalog contain over 100,000 disease- or trait-associated variants for rare and common disease with a $p<10^{-5}$ [11,12]. A small number of these variants have clinical utility for disease diagnosis, prognosis, or treatment.

The strong interactions between gene, diet, and disease first became apparent in the 1930s with the identification of phenylketonuria (PKU), a prototypical rare Mendelian disorder characterized by mutations in $P A H$ and a deficiency in phenylalanine metabolism $[13,14]$. In individuals with PKU, the buildup of phenylalanine derived from the diet becomes toxic and lethal [15]. Starting after birth, the major approach to lifelong treatment is a modified diet with low levels of phenylalanine [16]. This clinical nutrition therapy is similar to other nutrition therapies for the treatment of galactosemia and hereditary fructose intolerance $[17,18]$.

Over the past two decades, advances in GWASs and studies with focused candidate gene panels have enabled scientists to more rapidly identify genetic variants in gene-diet interactions and their associations with disease. This new capability has driven the emergence of the field of nutrigenetics [19]. Nutrigenetics assesses how a person responds to specific nutrients based on the variation within their genome. Many studies and trials have identified nutrigenetic variants associated with common diseases such as colorectal cancer, obesity, type 2 diabetes, and cardiovascular disease to name a few [20-23].

The number of publications in nutrigenetics has steadily increased over the past 17 years (Figure 1). Despite a significant amount of research in this field, the data have not been systematized into an accepted model to assess a person's genetics acquired by panel genotyping, single nucleotide polymorphism (SNP) microarrays, whole-exome sequencing, or whole-genome sequencing. The nutrigenetics.net database is a public collection of nutrigenetics literature. Most of the SNPs related to nutrigenetics are not present in other structured databases such as ClinVar, LOVD, and HGMD. These structured databases hold limited nutrigenetic data, but house clinical SNPs, disease-associated SNPs, and human genetic variation data related to traits and behavior [24-27]. 


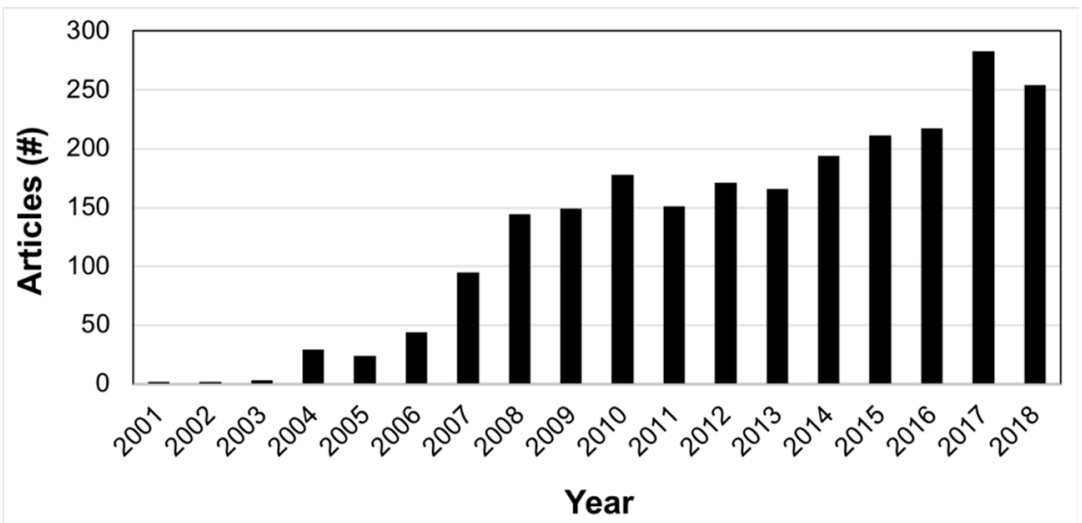

Figure 1. Bar graph of the nutrigenetics publication trend. The bar graph shows the number of nutrigenetic publications per year, beginning in 2001. The total number of papers is 2,317 . Abstracts were identified by querying PubMed, with terms related to nutrigenetics and disease. Examples are indicated in the Materials and Methods section.

Several nutrigenetic companies have emerged with goals of prescribing food intake and exercise with genetics. These companies offer clients genotyping, and/or secondary data analysis. The results are then processed to suggest personalized nutritional modification strategies. However, this new field is not without controversy with some criticism of nutrigenetic testing companies [28-30]. However, others have pointed out that some of the criticisms are not factually based and are potentially damaging to private interests [31,32]. Thus, the challenge remains to improve upon and disclose the value of genetic testing procedures based on quality scientific evidence.

The main goal of this study is to prioritize SNPs for validation of genotype-directed nutrition dietary modifications to reduce the burden of disease risk in healthy people based upon genetic variant frequencies in global superpopulations. Genotype-directed nutrition was previously defined and the five major superpopulations are as defined in the 1000 genomes project $[33,34]$. Herein, the term "genotype-directed nutrition" reflects dietary modifications based upon common nutrigenetic variants with high frequencies in at least one human population. This is in contrast to personalized nutrition, where the diet is precisely designed for each individual and not a population. The proposed population stratification and genotype-directed nutrition could be further tested and if validated provide significant health benefits. We do not know of another report that globally prioritizes nutrigenetic studies for validation studies based upon SNP frequency. Note, that this effort is focused on diets for normal people, and not for clinical nutrient therapies, which are medical treatments and should be subject to stricter clinical validation studies.

\section{Results}

\subsection{Literature Annotation for Nutrigenetic Database}

The first step needed for creating genetic-driven nutrition modification was to create a nutrigenetic database extracting information from published articles into structured data. There were $\sim 2,300$ nutrigenetics articles published since 2001 (Figure 1). A database was built from published studies employing well-defined criteria for variant selection following the process schema diagram in Figure 2. 


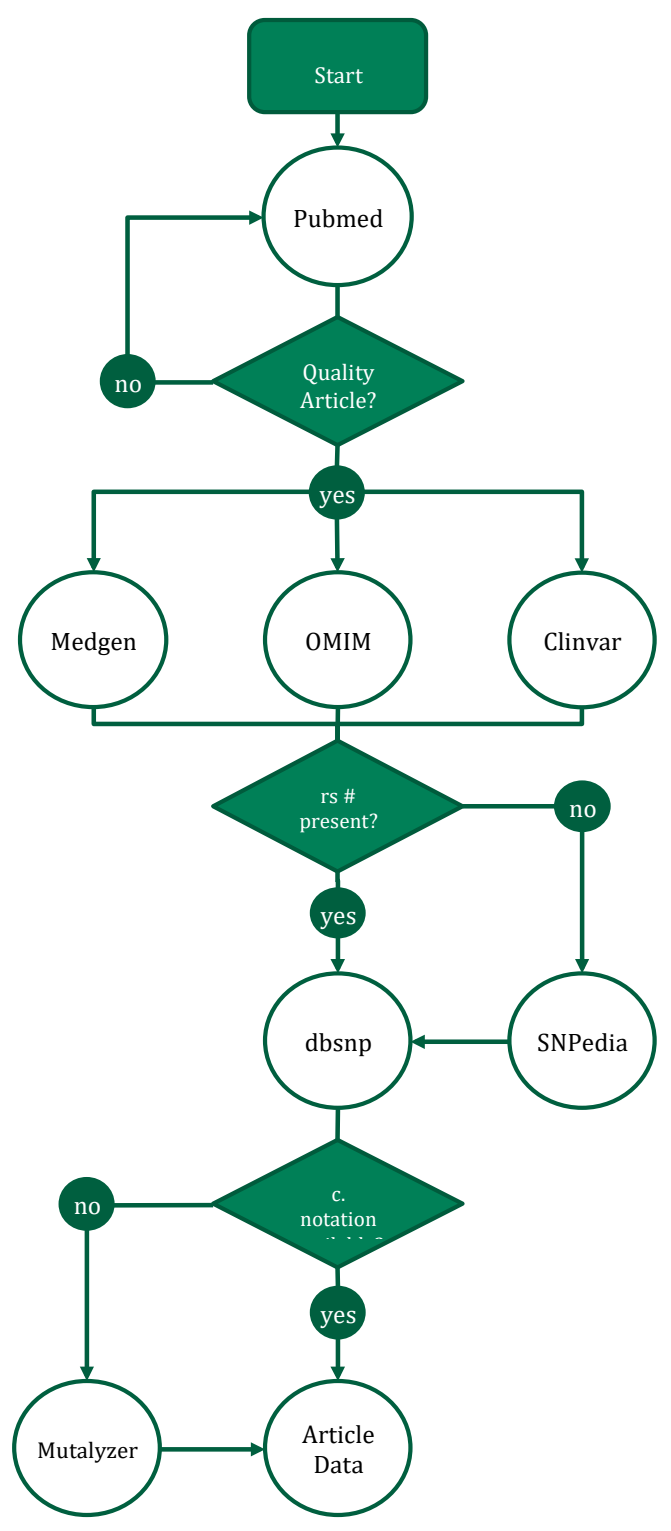

Figure 2. Nutrigenetic paper annotation workflow.

We evaluated each article for quality based on reported odds-ratios and $p$-values and optional confidence intervals. Any nutrigenetics study reporting a $p$-value $(p<0.05)$ was considered for further annotation [35]. Any GWAS was considered if it met the $p<5 \times 10^{-8}$ threshold for genome-wide significance, which incorporates the Bonferroni correction for multiple testing. An annotation entry also required reported log odds ratio $(0.97<$ OR $>1.03)$ for an association between a nutrient and a disease or endophenotype outcome. We selected articles that had a log-odds ratio for the disease or endophenotype and also for the effect of the nutrient intake and variant on the disease risk. Protective or risk factor variants had odds ratios for gene-diet interactions greater than that of the nutrigenetic population and vice-versa for a protective variant. Since confidence intervals are not always represented in articles, and while useful, they are not essential to the annotation process, thus can be entered as null in the database.

Articles meeting these criteria were next cross-referenced with MedGen, Online Mendelian Inheritance of Man (OMIM), and ClinVar. If the variant did not have a dbSNP identifier, one was obtained from SNPedia. If C. notation for the variant was not available, the information was obtained with Mutalyzer. The PubMed identifier was also recorded. 


\subsection{Summary Statistics for Nutrigenetic Variants}

The current database version has 156 gene-diet interactions with 101 unique variants in 84 genes passing the annotation quality criteria (Table 1). These variants account 145 nutrient intake or dietary suggestions, resulting in 290 total entries. Multiple entries can come from a study due to multiple variants reaching significance or multiple diet groups accompanying a particular variant within the same study. This set of variants accounted for the risk of 38 phenotypes, most of which were diseases, although some constitute endophenotypes. The ORs ranged from 0.07 to 35 with most SNPs $(67 \%)$ increasing risk for the phenotype.

Table 1. Statistics for construction of the nutrigenetic database.

\begin{tabular}{cc}
\hline Category & ${ }^{2}$ Number \\
\hline Articles & 67 \\
\hline Annotations & 156 \\
\hline Phenotypes & 36 \\
\hline Genes & 84 \\
\hline${ }^{1}$ SNPs & 101 \\
\hline Protective & 52 \\
\hline Risk & 104 \\
\hline 1 OR range (Avg) & $0.07-35(2.17)$ \\
\hline P-value range (Avg) & $3.5 \times 10^{-5}-0.05(0.018)$ \\
\hline Diet types & 106 \\
\hline Participants range (Avg) & $1-16,624(1106)$
\end{tabular}

Note: ${ }^{1}$ Abbreviations are: SNP = single nucleotide polymorphism; OR = Odds ratio; Avg = average; ${ }^{2}$ Numbers in parentheses are averages.

An example disease, colorectal cancer, is associated with 23 unique variants and affected by 34 different gene-nutrient interactions. The majority of the variants correlate with an increased risk of disease, which can be mitigated by nutrient intake. Folate was consistently identified in many gene-diet interactions, increasing or lowering disease risk dependent upon the amount ingested. A cohort study examining colorectal cancer identified gene-diet interaction between the MTHFR gene and folate intake in Koreans. Carriers of the $\mathrm{C}$ base in the C677T SNP variant had a decreased risk with high intake of folate ( $>282 \mu \mathrm{g} / \mathrm{d}$ : OR $0.62, p<0.002$, confidence interval [CI] 95\%: 0.46-0.84) [36]. This is just one example disease where evidenced-based modifications to a person's diet could ameliorate the increased risk of disease [36].

\subsection{Genotype-Directed Nutrition Prioritization for Superpopulations Based on Nutrigenetic Variants}

Studies of gene-diet interactions are designed to generally identify common variants in the population that have detectable effects from prevalent SNPs. Thus, it is no surprise that our nutrigenetics database has $37 \%$ of nutrigenetic SNPs with global SNP frequencies for nutrigenetic variants $>50 \%$, with all variants having a wide range of frequencies (Figure 3). Furthermore, of the 101 unique variants, six had global SNP frequencies $>90 \%$. We reasoned that these variants could be utilized to improve population health. Therefore, we further examined how SNP frequencies of these variants varied among superpopulations (Africans, Americans, East Asians, Europeans, and South Asians) by analyzing the 1,000 genomes phase 3 data. There were 17 SNPs where comparison of two superpopulation had an $\mathrm{F}_{\mathrm{ST}}>0.5$, with values ranging up to 0.71 . 


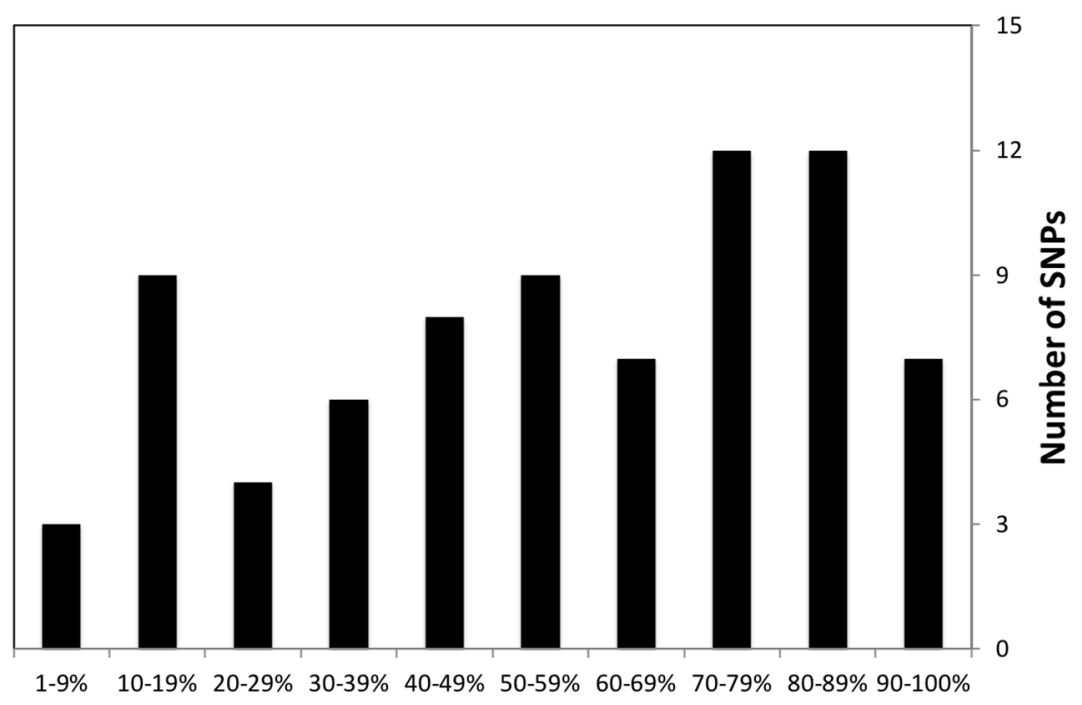

SNP frequency range

Figure 3. Bar chart with the number of annotated nutrigenetic variants vs. the frequency range. Variant data for superpopulation frequency ranges is from the phase III release of the 1000 Genomes Project [37].

An example in Table 2 shows that a variant in the $V D R$ gene is much less frequent in Africans with the $\mathrm{F}_{\mathrm{ST}}$ for all superpopulations ranging from 0.06 to 0.71 . We, therefore, examined those variants with SNP frequencies of above $50 \%$ in at least one superpopulation (Table 2).

Studies on these SNPs suggest nutritional changes for the superpopulations that may have a population-wide benefit for the diseases associated with these variants. For all populations, low fat, high n-3 PUFA, low n-6 fatty acids, and high folate may reduce the global disease risk for five common disorders (Table 3 ). While high $\mathrm{n}-6$ fatty acids are a general suggestion, people with this genetic variant might consider low $\mathrm{n}-6$ fatty acids in their diets [38]. There are also several superpopulation specific suggestions. For example, low calcium $(<680 \mathrm{mg} /$ day), low alcohol and high Vitamin D consumption for East Asians may be a dietary means to reduce population incidence of prostate cancer and obesity. This may require stratification by subgroups as addressed in the discussion section. 
Table 2. Frequencies for select SNPs with $>50 \%$ population difference.

\begin{tabular}{|c|c|c|c|c|c|c|c|c|c|}
\hline \multirow{2}{*}{${ }^{2} \mathrm{dbSNP}$ ID } & \multirow{2}{*}{ Gene } & \multirow{2}{*}{ Disease } & \multirow{2}{*}{ Dietary Change } & \multicolumn{6}{|c|}{ 1,2,3 Superpopulation SNP Frequency } \\
\hline & & & & ALL & AFR & AMR & EAS & EUR & SAS \\
\hline rs9997745 & ACSL1 & Metabolic Syndrome & $\begin{array}{c}{ }^{1} \text { Low-fat }(<35 \% \text { energy), } \\
\text { high-PUFA diet }(>5.5 \% \text { energy) }\end{array}$ & 78 & 40 & 87 & 100 & 85 & 93 \\
\hline rs6008259 & PPARA & Hypercholesterolemia & Low n-6 fatty Acid ( $\leq 7.99 \mathrm{~g} /$ day $)$ & 73 & 86 & 24 & 100 & 82 & 92 \\
\hline rs6087990 & DNMT3B & Colorectal Cancer & 1,4 High RBC folate & 68 & 76 & 63 & 92 & 37 & 68 \\
\hline rs3790433 & $L E P R$ & Metabolic Syndrome & 1,5 Low n-6 PUFA, high n-3 PUFA & 59 & 23 & 67 & 84 & 77 & 58 \\
\hline rs11568820 & $V D R$ & Prostate Cancer & Low calcium $(<680 \mathrm{mg} /$ day $)$ & 54 & 11 & 82 & 60 & 77 & 64 \\
\hline rs512535 & $A P O B$ & Metabolic Syndrome & Low fat $(<35 \%$ energy) & 53 & 19 & 51 & 81 & 51 & 73 \\
\hline rs10495563 & ADAM17 & Obesity & ${ }^{6}$ Low n-6 fatty Acid & 52 & 30 & 56 & 90 & 34 & 58 \\
\hline rs2287161 & CRY1 & Metabolic Syndrome & $\begin{array}{c}\text { Low carbohydrate }(\% \text { of energy } \\
\text { intake }<41.7 \%)\end{array}$ & 46 & 64 & 52 & 13 & 45 & 54 \\
\hline rs3827730 & FAF1 & Alcohol Dependence & ${ }^{7}$ Low amounts of alcohol & 38 & 7 & 52 & 79 & 35 & 28 \\
\hline rs2424913 & DNMT3B & $\begin{array}{l}\text { Adenoma, Colorectal } \\
\text { Cancer }\end{array}$ & No alcohol & 31 & 33 & 36 & 1 & 59 & 29 \\
\hline rs1801181 & CBS & Colorectal Cancer & 1,4 High RBC folate & 30 & 2 & 19 & 57 & 39 & 36 \\
\hline rs2424909 & DNMT3B & Colorectal Cancer & $\begin{array}{c}\text { Moderate alcohol }>0 \text { and }<1.7 \\
\text { drinks/week }\end{array}$ & 28 & 8 & 36 & 8 & 63 & 31 \\
\hline rs1378942 & CSK & Hypertension & ${ }^{1} 1.8 \mathrm{~g} /$ day of EPA and DHA & 24 & 3 & 33 & 18 & 61 & 16 \\
\hline rs2168784 & (Intergenic) & Alcohol dependence & no alcoholic drinks/week & 24 & 62 & 10 & 9 & 10 & 13 \\
\hline rs1229984 & $A D H 1 B$ & Alcohol dependence & no alcoholic drinks/week & 16 & 0 & 6 & 70 & 3 & 2 \\
\hline rs75038630 & NADSYN1 & $\begin{array}{l}\text { Abnormal Eating } \\
\text { Behavior }\end{array}$ & High vitamin $\mathrm{D}(>75 \mathrm{nmol} / \mathrm{L})$ & 2 & 0 & 4 & 100 & 6 & 3 \\
\hline
\end{tabular}

Note: ${ }^{1}$ Abbreviations are as in Table 1 and: PUFA = polyunsaturated fatty acid; RBC $=$ red blood cell; $\mathrm{EPA}=$ eicosapentaenoic acid; DHA = docosahexaenoic acid; $\mathrm{g}=$ gram; $\mathrm{mg}=$ milligram; $\mathrm{L}=$ liter; population abbreviations are defined in text. ${ }^{2}$ SNPs with FST $>0.5$ for two superpopulations. ${ }^{3}$ SNPs with a $>50 \%$ frequency are shaded gray. ${ }^{4}$ Low levels of RBC folate is defined as $(<484 \mathrm{ng} / \mathrm{mL})$ and associated with a risk, therefore, high levels of folate consumption should offset this risk and are reported as high RBC folate. ${ }^{5}$ Low PUFA status $(<45.85 \%$ of total measured fatty acids) if the diet is low (less than the median) plasma n-3 and high (n-6) PUFA. ${ }^{6}$ Undefined amount in the article. ${ }^{7}$ Dietary change: non-alcohol dependence or low occurrence of drinking alcohol. 
Table 3. Nutrigenetic dietary suggestions for superpopulations.

\begin{tabular}{|c|c|c|}
\hline Category & ${ }^{1}$ Diseases & ${ }^{1,2}$ Dietary Suggestion \\
\hline All & $\begin{array}{l}\text { Metabolic Syndrome, } \\
\text { Hypercholesterolemia, Colorectal } \\
\text { Cancer, Prostate Cancer, Obesity }\end{array}$ & $\begin{array}{c}\text { Low-fat }(<35 \% \text { energy }) \text {, High-PUFA diet }(>5.5 \% \\
\text { energy), Low } \mathrm{n}-6 \text { Fatty Acid }(\leq 7.99 \mathrm{~g} / \text { day }), \text { Low } \\
\text { Calcium }(<680 \mathrm{mg} / \text { day })\end{array}$ \\
\hline AFR & $\begin{array}{l}\text { Hypercholesterolemia, Alcohol } \\
\text { dependence }\end{array}$ & $\begin{array}{c}\text { Low n-6 Fatty Acid ( } \leq 7.99 \mathrm{~g} / \text { day }), 0 \text { alcoholic } \\
\text { drinks } / \text { week }\end{array}$ \\
\hline AMR & $\begin{array}{l}\text { Colorectal Cancer, Prostate Cancer, } \\
\text { Obesity, Alcohol Dependence }\end{array}$ & $\begin{array}{l}\text { High PUFA, Low Calcium }(<680 \mathrm{mg} / \text { day }),{ }^{3} \text { Low } \\
\text { n-6 Fatty Acid }\end{array}$ \\
\hline EAS & $\begin{array}{c}\text { Hypercholesterolemia, Prostate } \\
\text { Cancer, Obesity, Alcohol Dependence, } \\
\text { Abnormal Eating Behavior }\end{array}$ & $\begin{array}{c}\text { Low n-6 Fatty Acid ( } \leq 7.99 \text { g/day), Low Calcium } \\
\text { (<680 mg/day), }{ }^{3} \text { Low n-6 Fatty Acid, High } \\
\text { vitamin D }(>75 \mathrm{nmol} / \mathrm{L})\end{array}$ \\
\hline EUR & $\begin{array}{l}\text { Hypercholesterolemia, Prostate } \\
\text { Cancer, Adenoma, Hypertension }\end{array}$ & $\begin{array}{l}\text { Low n-6 Fatty Acid ( } \leq 7.99 \mathrm{~g} / \text { day }), \text { Low Calcium } \\
(<680 \mathrm{mg} / \text { day), } 1.8 \mathrm{~g} / \text { day of EPA and DHA }\end{array}$ \\
\hline SAS & $\begin{array}{l}\text { Hypercholesterolemia, Prostate } \\
\text { Cancer, Obesity }\end{array}$ & $\begin{array}{c}\text { Low n-6 Fatty Acid ( } \leq 7.99 \mathrm{~g} / \text { day), Low Calcium } \\
(<680 \mathrm{mg} / \text { day }),{ }^{3} \text { Low n-6 Fatty Acid }\end{array}$ \\
\hline
\end{tabular}

\section{Discussion}

The human condition is not just affected by genes, as many traits and conditions are also affected by physical location, environmental exposure, exercise, microbial interactions, and diet. Two prospects are information and genetic-driven, personalized medicine and prevention. While there are several approaches to prevention, in this article, we focus on genetic-driven food and nutrient intake as a source of prevention in the emerging field of nutrigenetics. Food is an important daily exposure factor that provides a wide variety of nutrients, non-nutrients, and even chemical contaminants that can modulate disease risks. For most human diseases, the risk is a combination of heritability, environmental factors from nutrient intake, and gene-diet interactions.

With the recent advances in commercialization of recreational genetics and further development of genetic investigations, there is a recent re-emergence of nutrigenetics companies. We considered the qualities of implementing scalable nutrigenetics that are needed for successful implementation. In this paper, we expand on three that we think are important, variant quality, collection of nutrigenetic data into a structured database, and how this information can be leveraged to prioritize studies for population-specific diets.

\subsection{Variant Quality}

Variant quality is a concern for several reasons that became more apparent as we annotated variants from the literature. Upon completion of our variant annotation database, the Global Nutrigenetics Knowledge Network (GNKN) reported standards for the quality and utility of nutrigenetic variants [29]. Many nutrigenetic research studies do not reach the rigor of the draft of standards proposed by the GNKN. Therefore, we revised the goal of this study to compile and analyze existing nutrigenetic studies to prioritize variants for validation studies. We had independently used a $p<0.05$ corrected for multiple testing criteria, a log odds ratio with a significant change, and confidence intervals.

There are several guidelines (STEGA, EGAPP, and GRADE) for clinical validity and utility of genetic tests [29,39-41]. For the current state of knowledge and difficulties in nutrigenetic studies, the clinical stringent criteria are generally too strict. They are designed for medical care, where errors in treatment could have life-threatening or life-altering effects. We emphasize that the purpose of our genotype-directed nutrition study is to prioritize variants to reduce disease susceptibility risk of healthy people with preventative or early detection strategies and not for clinical medicine. 
Some additional GNKN guidelines will be useful for classification of nutrigenetic variants. In particular, our variants should be further characterized for the hierarchical level of evidence supporting the variant marker, as well as the magnitude of effect as suggested by EGAPP [39]. The European Food Safety Authority (EFSA) scientific validity guideline is based on a number of studies, rather than a statistical outcome from a meta-analysis, which has a stronger scientific rationale [29]. The framework does not include a model to classify more complex metrics of genetic architecture such as genetic and polygenic risk scores. These metrics are geared toward susceptibility, which in general explain more of the heritability for common traits, conditions, and behaviors such as nutrient intake. These metrics are better suited to evaluate risk and are becoming rapidly accepted as approaches of choice for susceptibility to common disease [42-44].

These criteria fit that of a rare variant, rather than a common variant. Given the generally low number of participants in nutrigenetics studies when compared to large clinical trials, it is difficult to identify rare variants that have large effects as is the case for Mendelian disorders. In fact, this is the claim of the blood group diet where there are alleles of large effect, but these blood type alleles are not rare. Nevertheless, rare variants are of limited utility for genotype-directed nutrition in large populations unless many are identified. Currently, there are only a few examples reported for Mendelian disorders, as exemplified earlier by mutations in the $P A H$ gene and clinical treatment of patients afflicted with PKU by dietary therapy $[16,45]$.

In general, the 1,000s of new GWAS studies over the past decade support a model for a common disease where there are many common variants of small effect sizes, perhaps triggered by a specific combination with a rare variant. A more common recent practice is to sum the smaller risk of these large sets of common variants associated with any affliction into a genetic or polygenic risk score. This better models the polygenic and heterotypic nature of common disease. The effect of food intake on common disease is more likely to resemble a common disease, thus may be better approached by genetic risk scores. However, the field of nutrigenetics is yet to adopt this approach. This is a limitation that will need to be addressed in the future and modeled in current guidelines.

\subsection{Nutrigenetics Database}

Nevertheless, within the context of these limitations, we sought a way in which we could take advantage of the growing number of nutrigenetics studies. There are well-developed nutrient databases, but no comprehensive nutrigenetics databases [46]. We developed a data model to capture critical nutrigenetic information and annotated $~ 156$ gene-diet interactions from a comprehensive review of the nutrigenetics literature. While all studies were statistically significant, we recognize that for most of them, the study size is of small by today's standards, may not have been repeated, and therefore, some results may not repeat in a larger study or a meta-analysis. Furthermore, compliance with nutrient intake may be challenging in these studies. One particular challenge was modeling ethnicity, epistasis and the broader applicability of variants identified in a study focused on a specific ethnic population. Nevertheless, the value of our nutrigenetics database is synergistic with other nutrition-related databases that are publicly available such as the U.S. Department of Agriculture (USDA) nutrient database and PhenolExplorer for phenol content in foods [47].

\subsection{Genotype-Directed Nutrition for Populations}

Many genetic studies focus on specific ethnic populations, or pedigrees to isolate variants from variable genetic backgrounds. Even though $\sim 100$ nutrigenetic variants met our quality stringency criteria for annotation, the knowledge gained from these genetic studies is not yet used in the design of population-specific diets. To explore whether this information could potentially be useful for adjusting diet design, we examined $\mathrm{F}_{\mathrm{ST}}$ values for human populations. A small group of the SNPs were common in all populations, while a larger subset had significant changes in SNP frequencies between populations. Since the gene-diet interaction SNP was the major SNP in one or more superpopulation this information could be used to suggest superpopulation-specific nutritional changes when compared 
to a recommended diet. The summation of this approach yielded a collection of nutrition suggestions for each superpopulation, which can be further tested for validation. Other aspects of nutrigenetics, such as ethics, food supply, and food safety would also need to be considered.

\subsection{Limitations}

While the potential of a nutrigenetic precision diet is an attractive and intuitive concept in the prevention and management of chronic diseases, there are several limitations that must be considered in the interpretation of these data.

We recognize that variant interpretation may be more complex as the gene-diet interactions may be more polygenic in nature, like common diseases. In this case, a genetic risk score may be more suitable than SNPs associations. Indeed, the problematic nature of using single SNPs to predict complex traits are well known [48]. Most current nutrigenetics studies are limited examining small population sizes and a portion of these studies may not repeat upon a more rigorous design. However, we are using these studies for prevention and not for clinical intervention, thus the bar for quality does not have to be as high. Nevertheless, ideally, validation studies on larger populations should be tested prior to implementing a nutrigenetic recommendation. There are also instances where different nutrigenetic variants may influence the same phenotype and dietary associations [22,49]. However, genetic risk may be better predicted at the group level, as suggested in this paper, rather than for individualized predictions [48].

The majority of nutrigenetic studies differ in study design, population demographics, and sample size, thus introducing bias. The SNPs identified from one ethnic group may not be more broadly generalizable to other populations due to epistasis. Many of these studies must be replicated in other population types since genetic variation across ancestries and geographical regions exist [50]. Furthermore, with the recent ease and frequency of human migration, the superpopulation dietary suggestions are based on SNP frequency, which is not applicable to 'interracial' populations. Potential solutions are to derive dietary suggestions from an individual superpopulation(s) of ancestral origin or to analyze an individual's genetic file.

Another limitation in the current field of nutrigenetics is research factors in the design of studies that identify variants. This includes the type of study design (e.g., meta-analysis, randomized trial, longitudinal, prospective, cross-sectional). Other characteristics such as outcome, effect size, population size, control groups, and confirmation by a separate research study should also be considered. Furthermore, conclusions drawn from a study with "significant" $p$-values are under scientific scrutiny and should also include effect sizes, Bayesian measures, and reproducibility with meta-analyses from multiple studies [51]. Certainly, our database is limited by the qualities of available studies and that is why we suggest that the data we collected and modeled be used primarily to prioritize hypotheses for future investigation.

Population-level dietary recommendation is standard practice and we propose that genotype-directed nutrition for genotypes with high frequencies in populations could provide significant health care savings and reduce morbidity and loss of productivity. However, another key consideration is that some nutrient suggestion may need to be codified for specific groups within the population. For example, nutrigenetic variant suggesting low calcium intake $(<680 \mathrm{mg} / \mathrm{dL})$ for healthy adults needs to be carefully considered for specific population groups such as infants, adolescents, pregnant women, postmenopausal women and the elder population where this suggestion may not be applicable or even harmful.

\section{Material and Methods}

\subsection{Data Sources for Nutrigenetic Variants}

The majority of nutrigenetics knowledge exists in free form text of peer-reviewed publications. Due to current limitations in interpretation and mining information out of the free-form text, we decided 
to adopt manual annotation, which, while more time consuming, has the advantage of better accuracy. We reviewed the current scientific literature regarding dietary nutrients and nutrigenetic variants.

The PubMed database was queried with keywords and phrases to collect relevant nutrigenetic articles. Examples of such query phrases included, but were not limited to, "nutrigenetic", "gene-diet interaction", "diet intake", "polymorphism", "consumption", and "nutrient intake and gene-diet interaction". We also searched for combinations of these keywords and queries where "diet" was replaced with "food source", "nutrient" or "mineral". These search queries required multiple variations to find the relevant articles for annotation. A second major source of nutrigenetic variants was the GWAS catalog [11,12].

Information in the primary literature or GWAS catalog was extracted into a nutrigenetic data model (see Results). Variants were cross-referenced to National Center for Biotechnology Information (NCBI) data such as the PubMed, Entrez Gene, and MedGen databases where applicable. Entrez Gene and GeneCards were sources of gene summaries. Diseases were referenced with OMIM. dbSNP provides SNP IDs for each variant, and for cross-reference with several other databases such as the 1000 Genomes Project.

All variants were entered with HGVS notation. For the $\mathrm{c}, \mathrm{p}$, and $\mathrm{g}$ fields, $\mathrm{c}$. is the nucleotide position in the gene, $p$. is the position of the amino acid substitution in the gene, and $g$. is the nucleotide position within the entire chromosome. The reference genome for the database is GRCh37.p13. Although there are newer reference genomes, data that were included from several other databases and websites were referenced against GRCh37.p13. The USDA nutrient database provided a source of nutrients in foods [46].

\subsection{Population Frequencies and $F_{S T}$ Values of Nutrigenetic Variants}

The frequencies for each SNP variant were retrieved from the 1000 Genomes Project, phase 3 browser running Ensembl version 80, and referenced against GRCh37. The 1000 Genomes Project, phase 3 utilizes more than $80 \mathrm{M}$ short variants with genotypes of 2504 individuals across 26 global populations [37]. The human superpopulations are all, African (AFR), Admixed American (AMR), East Asian (EAS), European (EUR), South Asian (SAS). SNP frequency data for human superpopulations were from the 1000 genomes project. The fixation index $\left(\mathrm{F}_{\mathrm{ST}}\right)$ values for pairs of superpopulations were calculated from SNP frequency data with Excel. $\mathrm{F}_{\mathrm{ST}}$ is calculated from the equation: $\mathrm{F}_{\mathrm{ST}}=\sigma^{2} \mathrm{~S} / \sigma^{2} \mathrm{~T}$ where $\sigma^{2} \mathrm{~S}$ is the variance in the subpopulation and $\sigma^{2} \mathrm{~T}$ is the variance in the total population. These values measure the differences in frequencies of the SNPs across subpopulations.

\subsection{Data Model}

Nutrigenetics variant data annotated from the literature, NCBI databases, and the USDA nutrient data was modeled in a MySQL database. The database has six tables (Figure 4). These include a user table ("User") (with an anonymized user ID), a table linking each user to the relevant nutrigenetic variant entries ("UserEntry"), the genetic variant table ("NutrigeneticsEntry"), a genotype table ("Genotype"), a dietary suggestion table, and a table with foods and nutrients relevant to the entries on the suggestion table ("FoodOrNutrient"). The "NutrigeneticsEntry" table contains general information about the database variants with gene summaries, the dbSNP ID, phenotype, and chromosomal position. Each entry in the "NutrigeneticsEntry" table corresponds to one or more entries in the "Genotype" table. These entries include information on the effected minor frequency SNPs, including SNPs and $p$-values, odds ratios, and confidence intervals for the variant-disease interaction.

Each entry in the "Genotype" table is associated with entries in the "foods and nutrients" table. This table contains information on each dietary suggestion, such as the suggestion type (which may be to consume a certain portion of a food, nutrient, or food group, or to monitor a particular endophenotype), PubMed ID, study description, population risk data, and the $p$-value, OR, and CIs for the variant-phenotype-diet interaction for the suggestion. Each "foods and nutrients" entry is, in turn, associated with multiple entries on the "FoodOrNutrient" table. This table contains the relevant 
USDA nutrient database information for the suggested foods, such as the number of servings needed to provide the suggested daily value of a nutrient and the food's nutrient content.

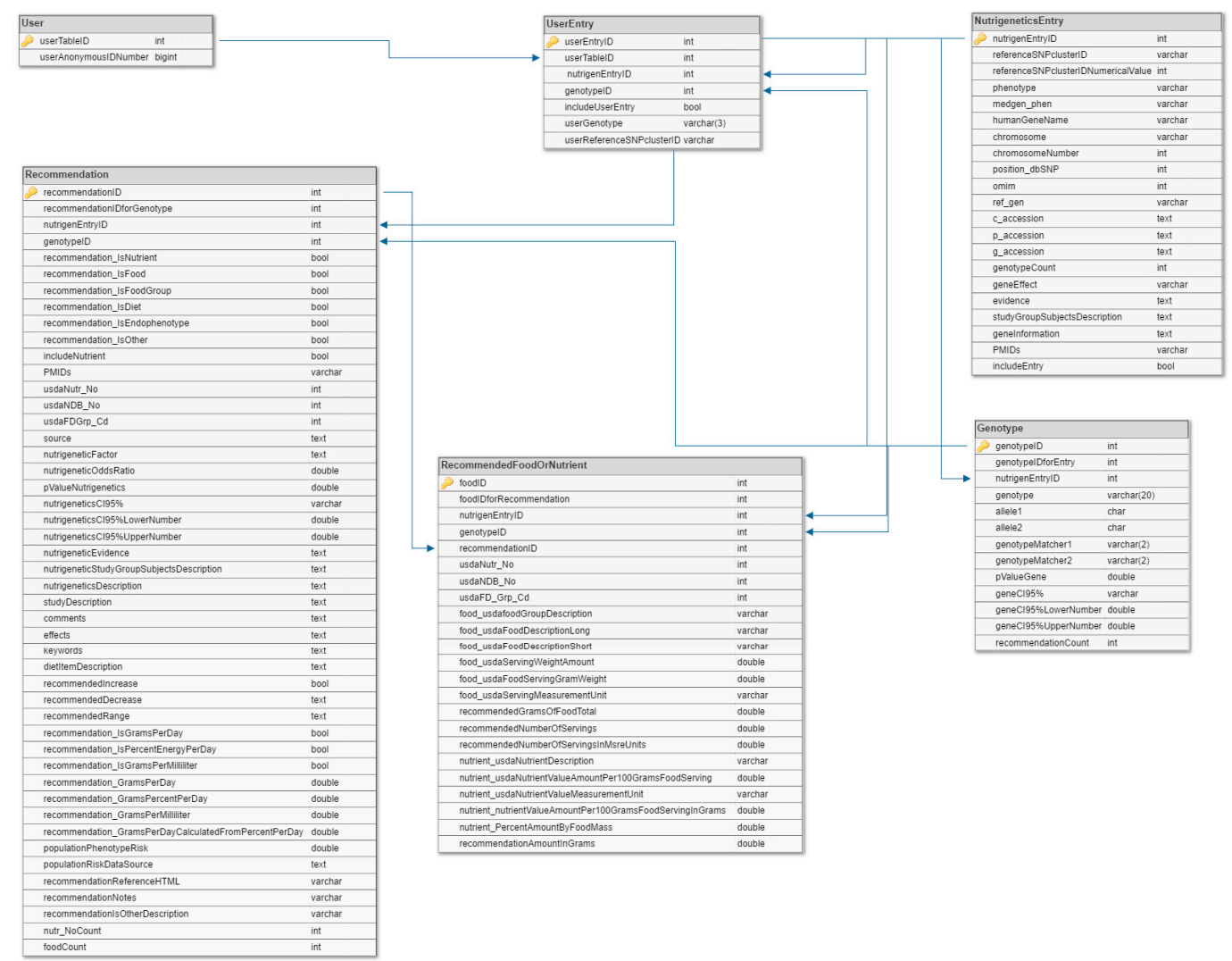

Figure 4. SQL schema for the nutrigenetic-nutrient database. Table names are in the dark grey header of each table. Tables contain fields with corresponding data types. The primary and foreign keys connecting tables are indicated by lines with arrows.

\section{Conclusions}

1. Nutrigenetic variants with high superpopulation frequencies can be used to prioritize dietary modifications for the purpose of reducing disease risk for human superpopulations with the potential for widespread health benefits.

2. The proposed superpopulation genotype-directed nutrition modifications will need to be validated in a research study.

\section{Data Availability}

The database is proprietary and licensed to a company, but may be used for research purposes. The database is available for collaboration upon request or for distribution through a license agreement.

Author Contributions: P.D.N. annotated nutrigenetic information from articles with some assistance from H.M.S. J.M.N. created the databases and coded the nutrigenetics computer program. A.B. provided nutritional consult and edited the paper with M.R.S. M.R.S. designed the study, performed the superpopulation analysis, obtained funding for the paper and wrote the manuscript with the assistance of P.D.N. and J.M.N.

Acknowledgments: This work was partially funded by the Nevada's Governor's Office of Economic Development and the National Science Foundation iCORPs program of the USA (Grant No. 1547526), the National Institutes of Health IDeA program of the USA (Grant No. GM121325), and a donation for the Prabhu endowed professorship. We thank Nephi Sanchez, James Timmins, and Anthony Pearson for discussions related to nutrigenetics.

Conflicts of Interest: M.R.S. is the CEO and founder of Food Genes and Me, LLC, the company that funded the construction of the database by P.D.N. and engineering of the nutrigenetics program by J.M.N. A.B., P.D.N. and H.M.S. have no competing financial interests. 


\section{References}

1. Lai, C.-Q. How much of human height is genetic and how much is due to nutrition? Sci. Am. 2006.

2. van den Berg, L.; Henneman, P.; Willems van Dijk, K.; Delemarre-van de Waal, H.A.; Oostra, B.A.; van Duijn, C.M.; Janssens, A.C.J.W. Heritability of dietary food intake patterns. Acta Diabetol. 2013, 50, 721-726. [CrossRef] [PubMed]

3. Li, J.; Liu, H.; Beaty, T.H.; Chen, H.; Caballero, B.; Wang, Y. Heritability of Children's Dietary Intakes: A Population-Based Twin Study in China. Twin Res. Hum. Genet. 2016, 19, 472-484. [CrossRef] [PubMed]

4. Mozaffarian, D.; Dashti, H.S.; Wojczynski, M.K.; Chu, A.Y.; Nettleton, J.A.; Männistö, S.; Kristiansson, K.; Reedik, M.; Lahti, J.; Houston, D.K.; et al. Genome-wide association meta-analysis of fish and EPA+DHA consumption in 17 US and European cohorts. PLoS ONE 2017, 12, e0186456. [CrossRef] [PubMed]

5. Harris, W.S.; Pottala, J.V.; Lacey, S.M.; Vasan, R.S.; Larson, M.G.; Robins, S.J. Clinical correlates and heritability of erythrocyte eicosapentaenoic and docosahexaenoic acid content in the Framingham Heart Study. Atherosclerosis 2012, 225, 425-431. [CrossRef] [PubMed]

6. Hasselbalch, A.L.; Silventoinen, K.; Keskitalo, K.; Pietiläinen, K.H.; Rissanen, A.; Heitmann, B.L.; Kyvik, K.O.; Sørensen, T.I.A.; Kaprio, J. Twin study of heritability of eating bread in Danish and Finnish men and women. Twin Res. Hum. Genet. 2010, 13, 163-167. [CrossRef] [PubMed]

7. Steck, S.E.; Keku, T.; Butler, L.M.; Galanko, J.; Massa, B.; Millikan, R.C.; Sandler, R.S. Polymorphisms in methionine synthase, methionine synthase reductase and serine hydroxymethyltransferase, folate and alcohol intake, and colon cancer risk. Lifestyle Genomics 2008, 1, 196-204. [CrossRef] [PubMed]

8. Abdelmagid, S.A.; Clarke, S.E.; Roke, K.; Nielsen, D.E.; Badawi, A.; El-Sohemy, A.; Mutch, D.M.; Ma, D.W. Ethnicity, sex, FADS genetic variation, and hormonal contraceptive use influence delta-5- and delta-6-desaturase indices and plasma docosahexaenoic acid concentration in young Canadian adults: A cross-sectional study. Nutr. Metab. 2015, 12, 14. [CrossRef]

9. Merritt, D.C.; Jamnik, J.; El-Sohemy, A. FTO genotype, dietary protein intake, and body weight in a multiethnic population of young adults: A cross-sectional study. Genes Nutr. 2018, 13, 4. [CrossRef]

10. García-Bailo, B.; Brenner, D.R.; Nielsen, D.; Lee, H.-J.; Domanski, D.; Kuzyk, M.; Borchers, C.H.; Badawi, A.; Karmali, M.A.; El-Sohemy, A. Dietary patterns and ethnicity are associated with distinct plasma proteomic groups. Am. J. Clin. Nutr. 2012, 95, 352-361. [CrossRef]

11. Welter, D.; MacArthur, J.; Morales, J.; Burdett, T.; Hall, P.; Junkins, H.; Klemm, A.; Flicek, P.; Manolio, T.; Hindorff, L.; et al. The NHGRI GWAS Catalog, a curated resource of SNP-trait associations. Nucleic Acids Res. 2014, 42, D1001-D1006. [CrossRef] [PubMed]

12. MacArthur, J.; Bowler, E.; Cerezo, M.; Gil, L.; Hall, P.; Hastings, E.; Junkins, H.; McMahon, A.; Milano, A.; Morales, J.; et al. The new NHGRI-EBI Catalog of published genome-wide association studies (GWAS Catalog). Nucleic Acids Res. 2017, 45, D896-D901. [CrossRef] [PubMed]

13. Fölling, A. Über Ausscheidung von Phenylbrenztraubensäure in den Harn als Stoffwechselanomalie in Verbindung mit Imbezillität. Hoppe Seyler's Z. Physiol. Chem. 1934, 227, 169-181. [CrossRef]

14. Penrose, L.; Quastel, J.H. Metabolic studies in phenylketonuria. Biochem. J. 1937, 31, 266-274. [CrossRef] [PubMed]

15. Scriver, C.R.; Byck, S.; Prevost, L.; Hoang, L. The phenylalanine hydroxylase locus: A marker for the history of phenylketonuria and human genetic diversity. PAH Mutation Analysis Consortium. Var. Hum. Genome 1996, 197, 73-90.

16. Woolf, L.I.; Griffiths, R.; Moncrieff, A. Treatment of phenylketonuria with a diet low in phenylalanine. Br. Med. J. 1955, 1, 57-64. [CrossRef] [PubMed]

17. Novelli, G.; Reichardt, J.K. Molecular basis of disorders of human galactose metabolism: Past, present, and future. Mol. Genet. Metab. 2000, 71, 62-65. [CrossRef]

18. Bouteldja, N.; Timson, D.J. The biochemical basis of hereditary fructose intolerance. J. Inherit. Metab. Dis. 2010, 33, 105-112. [CrossRef]

19. Peregrin, T. The new frontier of nutrition science: Nutrigenomics. J. Am. Diet Assoc. 2001, $101,1306$. [CrossRef]

20. Vargas, A.J.; Wertheim, B.C.; Gerner, E.W.; Thomson, C.A.; Rock, C.L.; Thompson, P.A. Dietary polyamine intake and risk of colorectal adenomatous polyps. Am. J. Clin. Nutr. 2012, 96, 133-141. [CrossRef]

21. Alfredo Martínez, J. Perspectives on personalized nutrition for obesity. Lifestyle Genomics 2014, 7, 1-3. 
22. Phillips, C.M.; Goumidi, L.; Bertrais, S.; Field, M.R.; Cupples, L.A.; Ordovas, J.M.; Defoort, C.; Lovegrove, J.A.; Drevon, C.A.; Gibney, M.J.; et al. Gene-nutrient interactions with dietary fat modulate the association between genetic variation of the ACSL1 gene and metabolic syndrome. J. Lipid Res. 2010, 51, 1793-1800. [CrossRef] [PubMed]

23. Zheng, J.-S.; Huang, T.; Li, K.; Chen, Y.; Xie, H.; Xu, D.; Sun, J.; Li, D. Modulation of the Association between the PEPD Variant and the Risk of Type 2 Diabetes by n-3 Fatty Acids in Chinese Hans. Lifestyle Genomics 2015, 8, 36-43. [CrossRef]

24. Landrum, M.J.; Lee, J.M.; Riley, G.R.; Jang, W.; Rubinstein, W.S.; Church, D.M.; Maglott, D.R. ClinVar: Public archive of relationships among sequence variation and human phenotype. Nucleic Acids Res. 2014, 42, D980-D985. [CrossRef]

25. Cooper, D.N.; Ball, E.V.; Krawczak, M. The human gene mutation database. Nucleic Acids Res. 1998, 26, 285-287. [CrossRef] [PubMed]

26. Küntzer, J.; Eggle, D.; Klostermann, S.; Burtscher, H. Human variation databases. Database 2010, 2010 , baq015. [CrossRef] [PubMed]

27. Fokkema, I.F.A.C.; Taschner, P.E.M.; Schaafsma, G.C.P.; Celli, J.; Laros, J.F.J.; den Dunnen, J.T. LOVD v.2.0: The next generation in gene variant databases. Hum. Mutat. 2011, 32, 557-563. [CrossRef] [PubMed]

28. Smith, G. At Home-DNA Tests: Marketing Scam or Medical Breakthrough; US Government Printong Office: Wshington, DC, USA, 2006; pp. 109-707.

29. Grimaldi, K.A.; van Ommen, B.; Ordovas, J.M.; Parnell, L.D.; Mathers, J.C.; Bendik, I.; Brennan, L.; Celis-Morales, C.; Cirillo, E.; Daniel, H.; et al. Proposed guidelines to evaluate scientific validity and evidence for genotype-based dietary advice. Genes Nutr. 2017, 12, 35. [CrossRef] [PubMed]

30. Kutz, G. Nutrigenetic Testing: Tests Purchased from Four Web Sites Mislead Consumers; GAO: Washington, DC, USA, 2006.

31. Castle, D. Genomic Nutritional Profiling: Innovation and Regulation in Nutrigenomics. Minn. J. Law Sci. Technol. 2008, 9, 37-60.

32. Castle, D.; Ries, N.M. Ethical, legal and social issues in nutrigenomics: The challenges of regulating service delivery and building health professional capacity. Mutat. Res. 2007, 622, 138-143. [CrossRef]

33. Clarke, L.; Fairley, S.; Zheng-Bradley, X.; Streeter, I.; Perry, E.; Lowy, E.; Tassé, A.-M.; Flicek, P. The international Genome sample resource (IGSR): A worldwide collection of genome variation incorporating the 1000 Genomes Project data. Nucleic Acids Res. 2017, 45, D854-D859. [CrossRef] [PubMed]

34. Ferguson, L.R.; De Caterina, R.; Görman, U.; Allayee, H.; Kohlmeier, M.; Prasad, C.; Choi, M.S.; Curi, R.; de Luis, D.A.; Gil, Á.; et al. Guide and Position of the International Society of Nutrigenetics/Nutrigenomics on Personalised Nutrition: Part 1-Fields of Precision Nutrition. Lifestyle Genomics 2016, 9, 12-27. [CrossRef] [PubMed]

35. du Prel, J.-B.; Hommel, G.; Röhrig, B.; Blettner, M. Confidence interval or p-value? Part 4 of a series on evaluation of scientific publications. Dtsch. Arztebl. Int. 2009, 106, 335-339. [CrossRef] [PubMed]

36. Kim, J.; Cho, Y.A.; Kim, D.-H.; Lee, B.-H.; Hwang, D.-Y.; Jeong, J.; Lee, H.-J.; Matsuo, K.; Tajima, K.; Ahn, Y.-O. Dietary intake of folate and alcohol, MTHFR C677T polymorphism, and colorectal cancer risk in Korea. Am. J. Clin. Nutr. 2012, 95, 405-412. [CrossRef] [PubMed]

37. Abecasis, G.R.; Auton, A.; Brooks, L.D.; DePristo, M.A.; Durbin, R.M.; Handsaker, R.E.; Kang, H.M.; Marth, G.T.; McVean, G.A. An integrated map of genetic variation from 1,092 human genomes. Nature 2012, 491, 56-65. [PubMed]

38. Junyent, M.; Parnell, L.D.; Lai, C.-Q.; Arnett, D.K.; Tsai, M.Y.; Kabagambe, E.K.; Straka, R.J.; Province, M.; An, P.; Smith, C.E.; et al. ADAM17_i33708A>G polymorphism interacts with dietary n-6 polyunsaturated fatty acids to modulate obesity risk in the Genetics of Lipid Lowering Drugs and Diet Network study. Nutr. Metab. Cardiovasc. Dis. 2010, 20, 698-705. [CrossRef] [PubMed]

39. Teutsch, S.M.; Bradley, L.A.; Palomaki, G.E.; Haddow, J.E.; Piper, M.; Calonge, N.; Dotson, W.D.; Douglas, M.P.; Berg, A.O. The Evaluation of Genomic Applications in Practice and Prevention (EGAPP) initiative: Methods of the EGAPP Working Group. Genet. Med. 2009, 11, 3-14. [CrossRef]

40. Little, J.; Higgins, J.P.T.; Ioannidis, J.P.A.; Moher, D.; Gagnon, F.; von Elm, E.; Khoury, M.J.; Cohen, B.; Davey-Smith, G.; Grimshaw, J.; et al. STrengthening the REporting of Genetic Association Studies (STREGA)—An Extension of the STROBE Statement. PLoS Med. 2009, 6, e1000022. [CrossRef] 
41. Rafiq, M.; Boccia, S. Application of the GRADE Approach in the Development of Guidelines and Recommendations in Genomic Medicine. Genomics Insights 2018, 11, 117863101775336. [CrossRef]

42. Conran, C.; Na, R.; Chen, H.; Jiang, D.; Lin, X.; Zheng, S.l.; Brendler, C.; Xu, J. Population-standardized genetic risk score: The SNP-based method of choice for inherited risk assessment of prostate cancer. Asian J. Androl. 2016, 18, 520 .

43. Dudbridge, F. Power and Predictive Accuracy of Polygenic Risk Scores. PLoS Genet. 2013, 9, e1003348. [CrossRef]

44. Wray, N.R.; Goddard, M.E.; Visscher, P.M. Prediction of individual genetic risk to disease from genome-wide association studies. Genome Res. 2007, 17, 1520-1528. [CrossRef] [PubMed]

45. Start, K. Treating phenylketonuria by a phenylalanine-free diet. Prof. Care Mother Child 1998, 8, 109-110. [PubMed]

46. Schakel, S.F.; Sievert, Y.A.; Buzzard, I.M. Sources of data for developing and maintaining a nutrient database. J. Am. Diet Assoc. 1988, 88, 1268-1271. [PubMed]

47. Neveu, V.; Perez-Jimenez, J.; Vos, F.; Crespy, V.; du Chaffaut, L.; Mennen, L.; Knox, C.; Eisner, R.; Cruz, J.; Wishart, D.; et al. Phenol-Explorer: An online comprehensive database on polyphenol contents in foods. Database 2010, 2010, bap024. [CrossRef] [PubMed]

48. Wray, N.R.; Yang, J.; Hayes, B.J.; Price, A.L.; Goddard, M.E.; Visscher, P.M. Pitfalls of predicting complex traits from SNPs. Nat. Rev. Genet. 2013, 14, 507-515. [CrossRef]

49. Guerreiro, C.S.; Ferreira, P.; Tavares, L.; Santos, P.M.; Neves, M.; Brito, M.; Cravo, M. Fatty Acids, IL6, and TNF $\alpha$ Polymorphisms: An Example of Nutrigenetics in Crohn's Disease. Am. J. Gastroenterol. 2009, 104, 2241-2249. [CrossRef]

50. Matullo, G.; Di Gaetano, C.; Guarrera, S. Next generation sequencing and rare genetic variants: From human population studies to medical genetics. Environ. Mol. Mutagen. 2013, 54, 518-532. [CrossRef]

51. Wasserstein, R.L.; Schirm, A.L.; Lazar, N.A. Moving to a World Beyond “ $p<0.05$. ”. Am. Stat. 2019, 73, 1-19.

(C) 2019 by the authors. Licensee MDPI, Basel, Switzerland. This article is an open access article distributed under the terms and conditions of the Creative Commons Attribution (CC BY) license (http://creativecommons.org/licenses/by/4.0/). 